\title{
The Status of Urban and Suburban Sprawl in Egypt and Iran
}

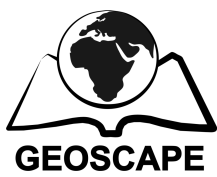

\author{
Amr Ah. Gouda ${ }^{1 *}$-Maryamsadat Hosseini ${ }^{2}-$ Houshmand E. Masoumi ${ }^{3}$ \\ ${ }^{1}$ First affiliation: Center for Technology and Society, Technische Universität Berlin, \\ Germany. Hardenbergstr. 16-18, Berlin 10623, Germany \\ Second affiliation: Architecture Dept., faculty of Engineering, Ain Shams University, \\ Sarayat St. 1, Abassia, Cairo, Egypt \\ *gouda@ztg.tu-berlin.de \\ ${ }^{2}$ Global Urban Studies, Rutgers University. NJ, USA \\ ${ }^{3}$ Center for Technology and Society, Technische Universität Berlin, \\ Hardenbergstr. 16-18, Berlin 10623, Germany
}

\begin{abstract}
The circumstances of urban sprawl in the Middle Eastern cities have been basically examined; now we are aware of the existence of a crawling sprawl in the growth pattern of the region's cities. Nevertheless, the extent and the causes of this phenomenon have not yet been clearly explained. Thus, two questions are still unanswered: (1) to what extent are the Middle Eastern cities sprawled?, (2) what are the main drivers of sprawl in the Middle East? This paper brings together several evidences from international and the national languages to provide explanation to the above. The findings show that urban and suburban sprawl is an inclusive pattern seen in a wide variety of city sizes, planning concepts, times, etc. Sprawl is not limited to large metropolitan areas; mid-sized and small cities of the region are also sprawling. Furthermore, administrative and planning reasons are the strongest causes of urban sprawl in the region.
\end{abstract}

Key words: urban sprawl, suburban sprawl, urbanization, urban land use, the Middle East

Highlights for public administration, management and planning:

- both large and mid- and small-sized cities are subject to urban sprawl in the Middle East

- political/planning decisions are crucial in urban sprawl patterns

Received: 11 Dec 2015 - Received in revised form: 25 Apr 2016 - Accepted: 2 May 2016

\section{Introduction}

Since 1937, when the term of 'urban sprawl' was introduced by Earle Draper (Wassmer 2002), voluminous literature has addressed the topic. Numerous definitions, spatial patterns, characteristics and attributes have been pinned to it. Conspicuously, the most cited definitions have American or European genesis, e.g. 'Akademie für Raumsforschung und Landesplannung', 'The European Environment Agency (EEA)', (Ewing et al. 2002; Jaeger et al. 2010; Sierra Club 1998), etc. A summation and comparison between the different definitions is in hand in the literature review of some publications (Franz et al. 2006;
Masoumi 2012a; Jaeger et al. 2010). In addition, the quantitative characterization and valuation of the phenomenon is available in Torrens (2008) and Ewing et al. 2002, which makes Urban sprawl a well-researched topic. Still, based on a multifarious literature review (books, scholars and newspapers in English, Arabic and Persian) in urban sprawl and its vicinities, the topic appears to be amorphous and nascent in the Middle East, despite the fact that its attributes are tangible.

One basic issue in this regard is that the main attributes of urban sprawl may be various in different contexts. Thus, the main characteristics of the Middle Eastern sprawl should be identified 
and compared to those of other contexts (see more discussions on this subject in Masoumi 2012a). However, before that, we should be ensured if the urban growth of the cities in the region, particularly large and medium ones, are not natural and can be classified as sprawl. Some recent studies depict existence of sprawl in urban development of Iranian cities as examples of similar cities in the region (Ahmadi et al. 2011; Azizpour et al. 2009; Masoumi 2014; Zanganeh Shahraki et al. 2011). Nevertheless, still several points remain unclear, i.e. the extent of urban sprawl in the Middle Eastern cities, as well as the drivers of sprawl.

Clarifying the above unclear issues is the objecttive of this paper. So far, evidence for showcasing different sprawl intensities in different regions of the world has been provided (Masoumi \& Roque 2015). In other words, we know that because of different socio-economics and planning systems and approaches, sprawl may be more intense or faster in some regions. However, despite discussing sprawl and its negative effects on the environment, finance, and resource, we do not have a comprehensive understanding of the extent of inclusiveness of sprawl, e.g. we are not aware that this pattern is an indication in larger cities, or mid-sized and small cities are also sprawling. Moreover, it is even less evident what societal and/or administrative motives are behind sprawl in the region. There are very few studies with this topic, so as a part of an on-going research, this paper explains some of the drivers.

\section{Methodology}

The paper is meant to provide answers to the following two questions: (1) to what extent are the Middle Eastern cities sprawled? (2) what are the main drivers of sprawl in the Middle East? Descriptive method such as library work on resources in English, Arabic, and Persian is employed to answer the research questions. Then the findings are brought together to enable the authors to interpret the background studies. Two major countries in the region, Iran and Egypt, are studied as observation countries including 15 cities discussed in the existing literature, the locations of which are depicted in Figure 1.

The study is based on library work bringing together literature from three languages of English, Arabic, and Persian (Farsi). Although urban sprawl has not been referred to as a clear and widely used phrase with a scientific meaning in both Persian and Arabic languages (as is discussed later in this article about Arabic), but many publications depicting an image of fast and uncontrolled urban growth have been discussed in this paper. In Persian, several phrases including two or three words have been used to present sprawl. Publications focusing on phenomena like "horizontal urban growth', 'uncontrolled urban development', and so on have been the topic of some of the papers reviewed in this study. Recently, even the word 'sprawl' has directly been applied to make it shorter in Persian. Publications that try to comprehensively monitor and encompass the typologies, causes and consequences of urban sprawl from a local vantage point are still lacking. To begin with, the nearest Arabic keyword to sprawl in meaning is tamadod, but it is rarely used and does not contingently imply negativity. Authors usually opt for the words Tawaso' or Zahf Omrany instead, with the first implicating a healthy urban development and the second primarily tackling encroachments upon agriculture lands. Also, the English term 'sprawl' is utilized to specify and characterize every undesirable and dysfunctional types of urban growth in Egypt, ranging from informal urbanization in the vicinity of historic plateaus (Hendrickx et al. 2013) to infringements upon the limited agriculture lands e.g. (Shaalan 2013; Shalaby 2012), with the vast majority adopting the second. Only, urban sprawl is not just any dysfunctional type of growth, it is a specific one (Ewing et al. 2002). A diminutive literature tries to cover and trace the various attributes of urban sprawl in Egypt, e.g. (Taubenböck 2009). Nevertheless, many features of urban sprawl are salient within some of the literature of other urban phenomena; e.g. urbanization, urban growth, urban transformation, spatial disintegration, informality, gated communities, upmarket residential areas, elite communities, etc. 


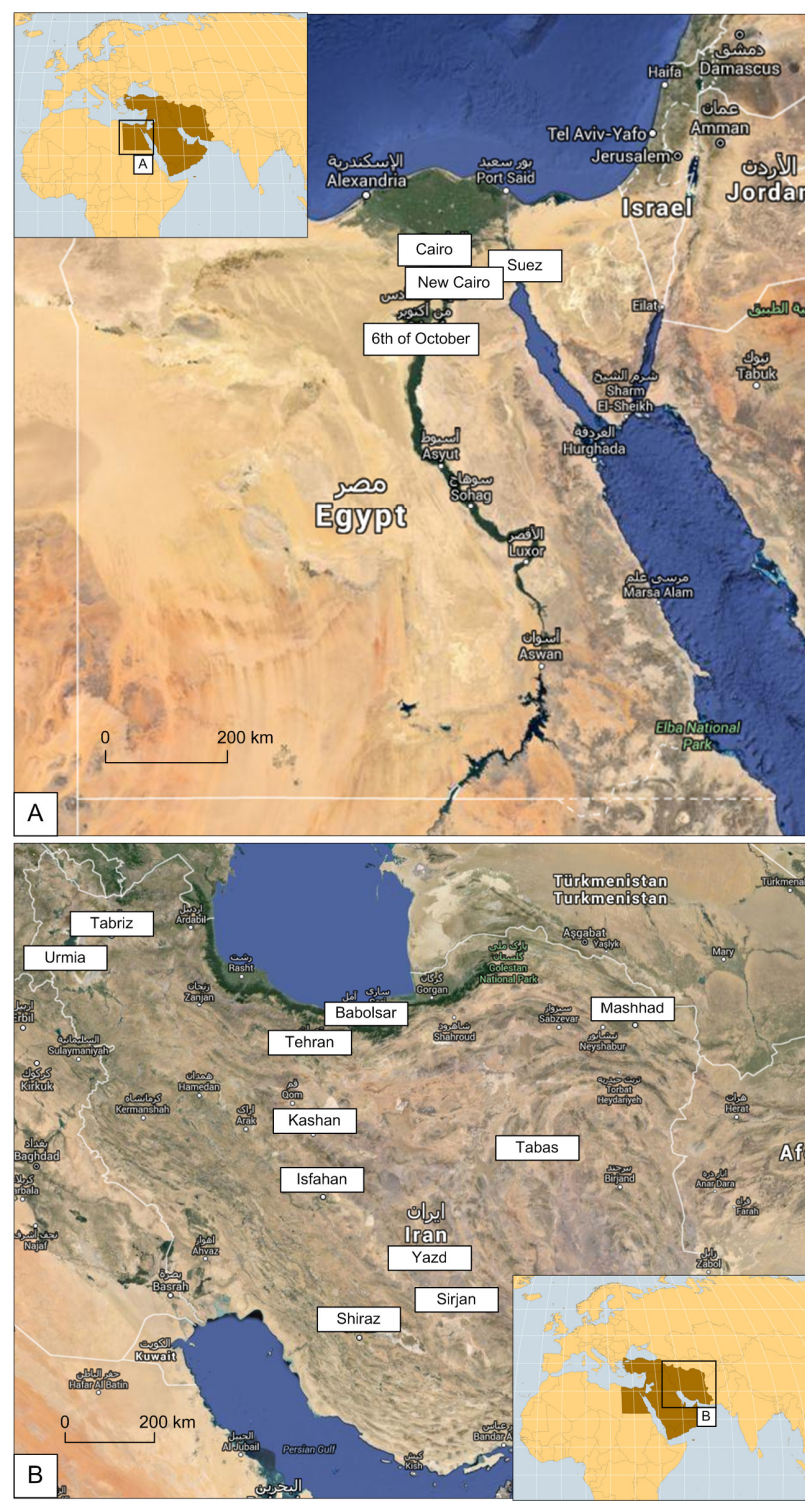

Fig. 1 - Location of cities in Egypt and Iran discussed in this study (source: Google Maps).

Since the subject is still young in the region, it is necessary to collect the existing sources, so that it forms a growing knowledge. For that, this paper takes descriptive approach to the topic. More precise metaanalysis of the existing literature including a wide range from online articles and newspapers to scientific essays and research papers remains for later investigations. The pre assumption of this study is that a fast planned or unplanned urban growth pattern exists in the Middle East that can be named as urban sprawl (Masoumi, 2014).

\section{Sprawl in the Western Context}

The simplest and most straightforward reason for the expansion of cities within the US is that people demand more space and so they move from city centers with restricted lot sizes to urban fringe and outskirts of cities. Air pollution, noise, heavy traffic and lack of green space are also among important qualities in relation with urban sprawl. However, the factors that accelerate this movement were the declining cost of transporttation and rise in the households' income alongside governmental tax, expenditure and zoning policies (Nechyba \& Walsh 2004).

Population growth, increase of income and decrease of commuting costs are the main causes of urban sprawl stated in the US context. Margo (1992) stated in his article that around fifty percent of the suburbanization in the period of 1950-1980 was due to the increase in people's income. In some studies, such as the works of Ewing et al. (2002) and Brueckner (2000), the change in the taste of an American, regarding the choice of living and working place, changes in residents' shopping habits, and also government or state mortgage loans are mentioned. In addition, most of the North American scholars, like Wassmer (2002), describe the pattern of sprawl as higher income residents moving to the fringe of urban areas. Thus, when discussing the reason behind such moves, they would point out the reasons that are in line with this trend, such as the increase in the rich's demand for larger and less expensive lands to build houses on, and such lands, are more likely to be found on the fringe of developed urban areas. Wassmer argues that beside the mentioned factors, higher income people preferred 'spatial separation' from the lower income and people with lower social status; this is one type of discrimination, which leads to urban sprawl. In fact, developers have strongly contributed to this segregation by creating exclusive neighbourhoods, which are home to expensive, high-end housing types, which have higher values than the mixed or more affordable areas. Local residents in an effort to preserve this value, oppose to any project that aims to provide more affordable housing in those areas (Duany et al. 2001). Racial discrimination is another commonly debated reason behind 
urban sprawl. According to several studies, there is a direct link between racial discrimination and urban sprawl. As the majority of the black and Hispanic population reside in the inner city parts, white people tend to reside as much as possible further away from them and thus they go to the outskirt of the city to build a community they feel safe in. This is often called 'flight from blight'. Suburbanization forces are generated by larger income and lower commuting costs and in the end, they result in reducing demand for the old city center houses and thus decreased their price and on top of that, weakened the incentives for revitalization and redevelopment of central areas. Ewing (1997) targets a pattern of sprawl that he called 'Los Angeles-style sprawl' and stated that the construction of federally subsidized highways together with low cost of using personal automobile has paved the way through movement to the suburbs.

Different trends and natures of urban sprawl have been identified in different geographical locations. There is a significant difference between urban sprawl in US and Europe. Latin American countries also have their own city expansion stories. The causes and consequences thus vary sharply. In a paper by Patacchini et al. (2009), five main causes of urban sprawl in the United States and Europe were discussed and compared. The first two, like in the previously reviewed papers, are income increase and decrease of commuting cost, which have the same effects in both US and Europe. The three remaining causes are:

- Increase in the employment rate, which is correlated with income increase and lead to the same result in both US and Europe.

- Higher crime rate that leads to higher sprawl in the US and lower sprawl in the Europe. The simple reason behind it is higher income people want to escape from the areas with higher crime rates. These areas in the US are located in the city centers and in Europe in the suburbs.

- An increase in the percentage of ethnic minorities in cities, which results in sprawl having increased in the US and decreased in Europe. The reasoning is quite obvious. White families do not like to live close to ethnic minorities and the minorities usually live in city centers in the US and in suburbs in Europe.

Europe has also experienced considerable growth in the level of income throughout the $20^{\text {th }}$ century. Macro and micro economic factors, demographic factors, housing preferences, inner city problems, transportation, and regulatory frameworks are mentioned as being the main drivers of urban sprawl in Europe by European Environment Agency and European Commission (2006).

Government policies also play a significant role in shaping this new development pattern. Taxing and zoning policies, subsidization of land and government loans are among the factors that encourage the urban sprawl. Brueckner (2000) emphasizes in several researches that property taxation contributes to urban sprawl especially "when the substitution between housing and other goods is low" (Brueckner \& Kim 2003). He suggests a land-tax regime to remedy this situation. Ewing (1997) states that "sprawl is the product of subsidies and other market imperfecttions".

From an economic perspective, people make the decision to move to the suburban areas, when the private benefits of the decentralized location are greater than the private costs of the non-central location. Nevertheless, what happens is they do not take into account the social costs of their decision. To understand whether this 'private decision' of a household is socially efficient, the public costs and benefits of this decision should be considered as well. The challenging part begins by understanding that many of these public benefits and costs have no directly observable monetary equivalents. Economists usually use the non-market goods evaluation methods to deal with this problem. These methods are categorized into two groups: indirect valuation methods and direct valuation methods known as revealed preferences and stated preferences respectively. Choice experiment is one of the methods which estimates the 'willingness to pay' to determine these monetary equivalents.

In the light of economic theories, monocentric and polycentric city models are among the most pronounced models, which tried to explain urban 
spatial structure. The monocentric city model was pioneered by Alonso (1964), Mills (1972) and Muth (1969). In this model, cities are assumed to be a circular residential area that has a single concentration of employment in central business district (CBD) in the center of the city, and the further we get away from the CBD, land rents and population density decline and lot sizes and commuting costs increase. This model then explains that the urban spatial structure is the result of trade-off between land price and commuting costs. The equilibrium happens when people find bigger lands with cheaper rents in the urban fringe to offset the increased commuting costs. As a result of this equilibrium, the population density in the center of the city decreases and the city expands further. The main point about this model is that it highlights the role of commuting costs for both consumers and producers together with the public investment in road infrastructures to explain the decrease in the urban population density and city expansion. The monocentric city model also suggests that the increase in the income level has resulted in falling density of population in a way that "income elasticity of demand for housing and land is sufficiently large relative to the income elasticity of commuting costs" (Nechyba \& Walsh 2004, p. 182).

Brueckner and Fansler (1983) based their study on a monocentric city model. The outcome of their study shows that income, price of farmlands and population accounts for almost 80 percent of urban sprawl. Later in 2005, McGrath got the same results with the same model and the updated data.

Although this model has provided a great basis for understanding the historical drivers of urban sprawl and analyzing urban patterns, further studies showed that the people's choice of place within the cities does depend on various considerations other than commuting costs like crime rates, air pollution, school qualities, access to public services etc. These factors which influence people's choices of a residential place can be classified in two major groups: push factors which make people leave the central places and pull factors which drag people from center of the cities into urban peripheries.

\section{The Extent of Sprawl in the Middle East}

The Middle Eastern urban sprawl has been already examined in case of morphology (Masoumi, 2012); four different urban street networks in the city of Kashan in central Iran shows how different are the urban morphology of the villages caught by the urban growth compared to that of different eras (Figure 2). However, the number of typological studies is not notable. Three types of urban sprawl are very clear in the region; unplanned sprawl along with inter-city roads or on the periphery of the cities is a common sprawl types in several countries of the region. An example is the unplanned developments along the Adana-Mersin-Antalya road in Turkey, which has led to consumption of agricultural land for urbanization purpose (Sandal \& Gürbüz 2003). Another type of sprawl is planned sprawl, which is an output of governmental planning and decision making, the example of which is seen in Iranian cities of Kashan and south of Yazd in form of unestablished new quarters lacking infrastructures and neighborhood centers (Masoumi 2012b). Another type of sprawl is seen in informal settlements, exemplified by Manshiet Nasser in Greater Cairo (Kipper \& Fischer 2009). Such settlements grow very rapidly, lacking basic living structures like schools that can be found in neighborhood or district centers. There may be other less obvious sprawl types that deserve to be studied in the future.

Severe urban sprawl has been observed in all the six large cities of Iran. Several studies focused on the urban sprawl and its consequences in these metropolitan areas such as Tehran (Rafiee et al. 2009; Roshan et al. 2009; 2010; Shahraki et al. 2012; Tayyebi et al. 2011; Zanganeh 2006), Mashhad (Hosseini 2008; Hosseini et al. 2010; Rafiee et al. 2009), Isfahan (Mokhtari et al. 2015; Soffianian et al. 2010), Tabriz (Azimi 2001; Pourmohammadi \& Jame Kasra 2011) and Shiraz (bin Ibrahim \& Sabet Sarvestani 2009; Movahed 2004; Sabet Sarvestani et al. 2011). Although much of the attention is set toward the unplanned horizontal growth of the large cities in Iran, mid-sized and small-large cities are also experiencing severe urban sprawl as well. 

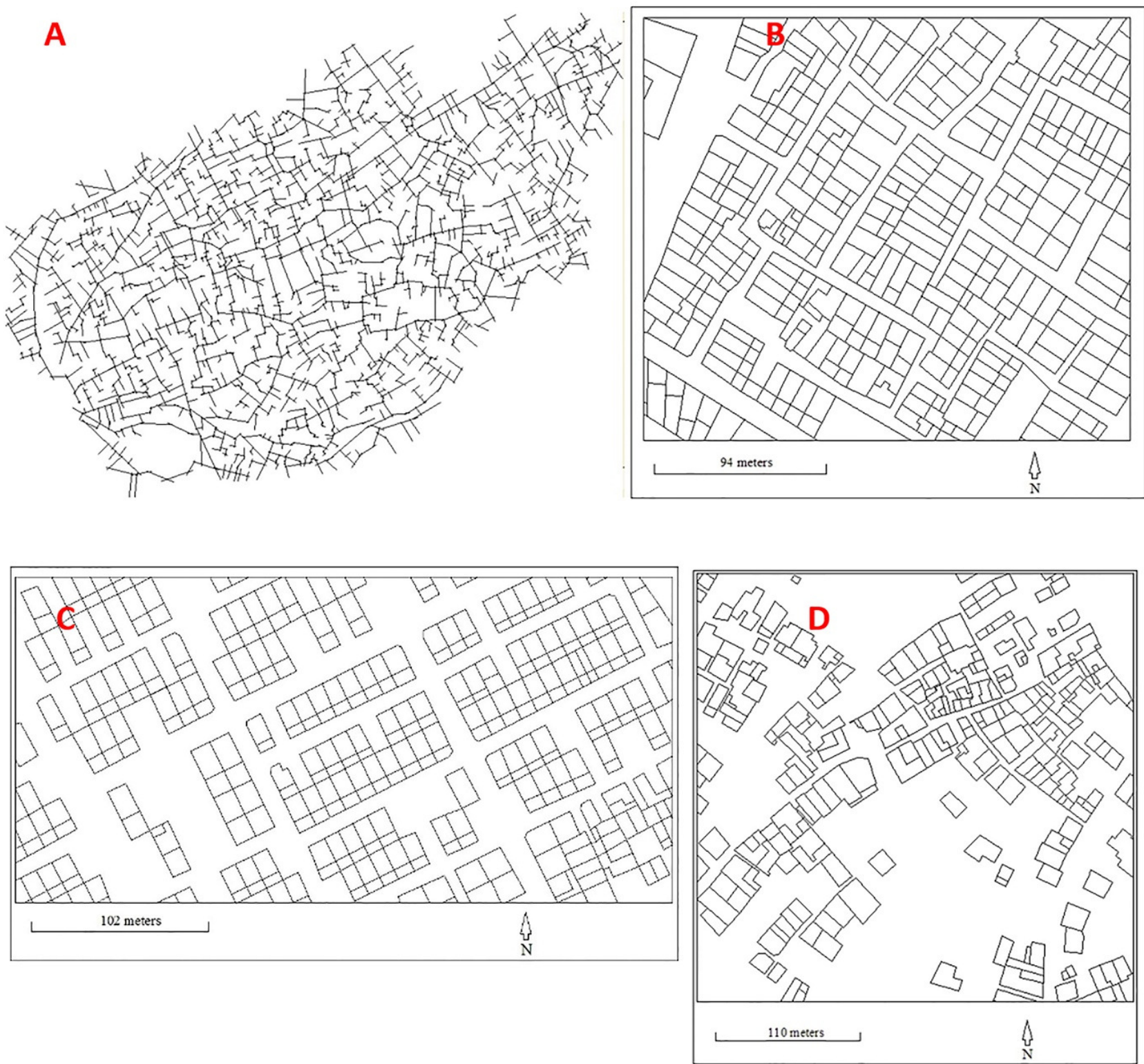

Fig. 2 - Different street networks belonging to different eras in Kashan; A: The street structure of the historical core of Kashan in late $19^{\text {th }}$ century, B: street network built in 1940-1980, C: quarters built after 1980, D: villages caught by the city and forming sprawl (Masoumi 2012a).

Masoumi (2014) investigated the existence of urban sprawl in the mid-sized cities of Iran and showed that Yazd and Kashan both have clear evidences of the sprawling cities like low density residential areas, rapid physical expansion of the city where the rate of physical expansion outnumbered the rate of population growth and lack of public amenities in the peripheral areas. Similar studies also verify the presence of urban sprawl in Yazd (Azizpour et al. 2009; Zanganeh Shahraki et al. 2011) and Kashan (Ahmadi et al. 2011). According to other studies, small cities like
Sirjan (Mahmoudabadi et al. 2013), Urmia (Mobaraki et al. 2012; 2013), Tabas (Ebrahim zade Asmin et al. 2010), and Babolsar (Ghanavati et al. 2012; Mirkatoli et al. 2011) are also sprawling rapidly. While many studies have focused on consequences of urban sprawl and its effects on tourism (Roshan et al. 2009), air pollution and climate change (Pourahmad et al. 2007; Roshan et al. 2010), etc., few papers addressed the drivers of it, although knowing the causes of sprawl plays a crucial role in preventing and making appropriate plans. 
From an institutional perspective, urban sprawl is not solely monitored by certain the region's organizations responsible for controlling it. Instead it is part of larger concepts like urbanization and urban planning. In Iran, sprawl and other urban phenomena are managed by the Ministry of Roads and Urban Planning, under which function several deputies such as the deputies of Urbanization and Architecture as well as Planning and Transport Economy. Moreover, there are several affiliated organizations and companies administered by the ministry that may deal with sprawl because of the nature of their missions. The examples are the New Cities Development Company and the Urban Development and Revitalization Company. The point is the weak connection between urban planning and transportation planning institutions, i.e. the Construction \& Development of Transportation Infrastructures Company has weak orientation to sprawl while transport infra-structure can work significantly for or against sprawl. However, the tasks of such transport institutions are more or less related to transport engineering, while integration of land use in transport planning remain neglected, hence concepts like sprawl are continuously considered as a purely urban planningrelated notion. In Egypt also urban sprawl is not exclusively controlled by the local governments; as they are only responsible for developing detailed urban plans and local roads network. The central government, holding most of the funds, are pretty much involved in sprawling phenomenon. The Ministry of Housing, Utilities, and Urban Development (MHUUD) and its affiliated organizations and authorities are responsible for general policy of planning and urban development and the construction of new cities. The Ministry of Transportation and its affiliated organizations which is responsible for intercity network and transporting. Both ministries are constructing multiple new cities and laying down thousands of kilometers of new roads which consequently accentuate urban sprawl. Currently, the central government is constructing around $4400 \mathrm{~km}$ of new roads representing $10 \%$ of the all the roads constructed since the $1920 \mathrm{~s}$ as a part of the president's plan (Ragheb, 2014). Within the Egyptian context two attributes of urban sprawl seem irrelevant: very low population densities (normally linked to the number of 12 people per acre for a cost effective public transportation reasons (Jaeger et al. 2010) and usage of private automobiles (Sierra Club 1998; USHUD 1999). Since only 5.3 percent of the Egypt's total area is inhabited (SIS 2013), mainly most of the Egyptian cities are highly densified; Greater Cairo region (GCR) has one of the highest population densities globally with 397 persons per ha (Japan International Cooperation Agency and Ministry of Housing, Utilities and Urban Development 2008), so a comparatively low population density is more compatible attribute for sprawling in this context rather than sticking to international figures.

Also, car ownership in Egypt is low in general, despite the fact that the number of vehicles doubled in only 14 years from 1993 to 2007 (The Cabinet 2007), car ownership was still 34.4 per 1000 capita in 2009, which is very low in comparison to 440 in USA, 510 in Germany (The World Bank 2015). The same rapid increase in car ownership in also seen in Iran; during 2002 and 2008 the figure changed from 23 to 112.9 cars per 1000 inhabitants (The World Bank 2015). Although it is still far from those of the USA and Germany, but it shows rapid jump. High rates of private car ownership and use can be a symptom of sprawl, but low ones mainly ascribed to affordability and unavailability reasons does not rule out sprawl, instead long travel durations can be contextually wise held also as a sprawling sign.

Based on qualitative characterization; urban sprawl is a de facto in Egypt. Still, it is intrinsic to acknowledge that urban sprawl is a multi-fold phenomenon that "has differing causes and consequences in different regions and regulatory contexts" (Jaeger et al. 2010). Likewise, sprawling morphologies might also differ in the Egyptian context, as it is hard to conceive that any phenomenon would preserve all its facile properties; recognizing the multifarious divergences in both its impetuses and repercussions. Furthermore, the dynamics and progression of the sprawling areas are inextricably pertinent to its characterization (Lopez \& Hynes 2003), because the attributes of urban sprawl can diminish by time through infill developments (Peiser 1989) or 
being encompassed within another urban agglomeration. Here, two main directions of sprawl are described below.

\subsection{Sprawling upon Arable Lands}

Only 7.9 million feddan ${ }^{1}$ (3.3 percent of Egypt's total land area) are agriculture lands (Kruseman \& Vullings 2007). Most of the cities within the Nile valley and delta are either encompassed by or contiguous to arable lands, usually highly productive ones. These lands are witnessing piecemeal but rampant erosion; between 1981 and $1988,340 \mathrm{~km}^{2}$ of arable lands were built upon in GCR alone (Robson et al. 2012). The phenomenon culminated indeed in whole Egypt in the three years succeeding $25^{\text {th }}$ January 2011 uprising (Arab Spring) with ministerial pronouncements estimating them by at least $215 \mathrm{~km}^{2}$ (Alnouby 2013) and up to $630 \mathrm{~km}^{2}$ (Hassan 2014).

Infringements upon arable lands in the vicinities of urban agglomerations exhibit many features of urban sprawl. To start with, they downsize and dissect the modicum of arable lands (Hereher 2012; Shalaby 2012) and disturb their ecosystem. On the micro level, they are developments beyond the edge of services upon relatively low priced lands. At incipient stages owing to the trepidation of governmental razing; infringements proliferate very slowly, typically in a patchy and disconnected manner, the first infringements serve as vanguards for the yet to follow ones as in Figure 3. Then, buildings seem to cluster for consolidation (Sims 2012) and at certain threshold the probability of razing diminishes and infringements spiral until most of the land subdivisions become concrete and masonry as in Figure 4. Although at that stage population densities become high, still many infringements retain some qualities of sprawling like being single use residential built areas which are devoid of any buzzing activity centers. So, they rely upon the nearest established urban agglomerations for services and job opportunities, In turn generating long travel durations due to the limited transport choices and low frequencies which are usually informal accompanied with the low accessibility of these areas in general.

\subsection{Sprawling upon the Desert}

The idea of 'Invading the Desert' goes back to nineteenth century (Ali 2003). Still, the actual commencement of the new desert cities project is ascribed to President Sadat's urban development paper in 1974. Desert cities should function as "growth poles for alternative development" (Sims 2012, pp. 73), obviate the chronic Egyptian urban malaises e.g. over-crowdedness, pollution and congestions, and steer urban growth away from encroachments upon arable lands (Ali 2003; Metwally \& Abdalla 2011). The currently established 22 new cities (Mahmoud \& Adel El-Sayed 2011) can be classified either according to their phase (phases one, two and three) (Farahat 2006) or their function (Free-standing, twin and satellite cities) (Ali 2003).

With uneven degrees, all new desert cities failed to achieve their targeted population: some are still vacant although their infrastructures are either finished or almost finished (these are infamous for 'ghost cities'); e.g. the city of New Aswan held 60 people in 2014 out of its targeted 70,000 in 2017 (Abd El-latif 2013). Other cities succeeded in attracting a minor fraction of their targeted population e.g. the new cities in GCR held 601,767 people in 2006 out of the expected 1.75 million people, still GCR cities are the most successful in terms of population as they hold 80 percent of all the desert cities population (Sims 2012). Paradoxically, the new desert cities that were originally planned to comprise low-cost state-subsidized housing alongside with middleclass subdivisions veered towards upmarket developments and gated communities themes in the 1990s. The boundaries and targeted population are being unflaggingly extended and increased not only in the GCR new cities but also in the 'ghost cities' e.g. 6378 feddans were added to the original (vacant) 3900 feddans of New Aswan in 2009. As for the GCR new cities which initially targeted holding around 2 million people (Fahmi \& Sutton 2008); currently their target is 16.74 million people (NUCA 2014). Unfortunately, this increase is not made through densification and compactness, rather the boundaries of some cities have been extended to astronomical level to maintain their current densities, 


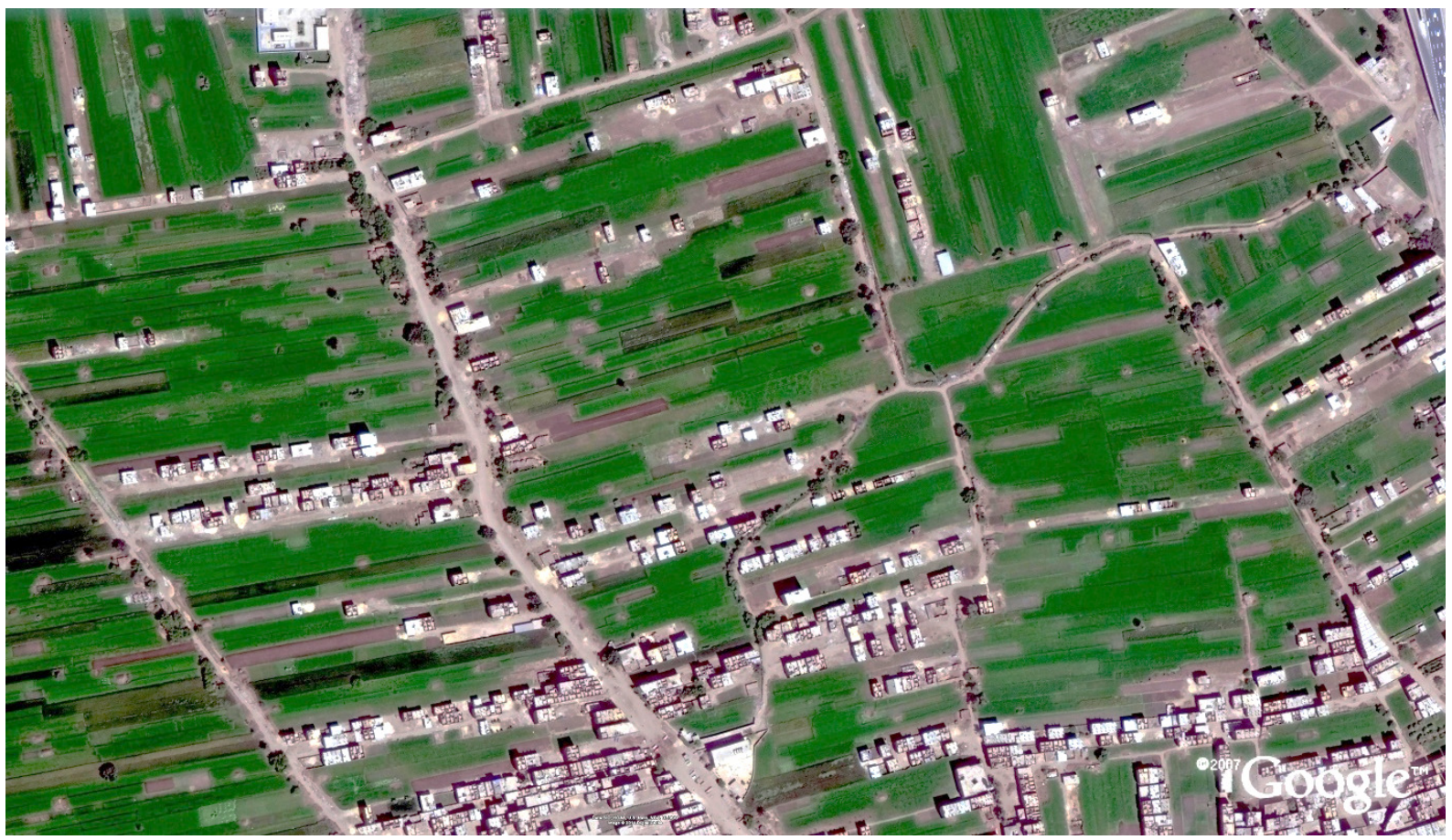

Fig. 3 - Incipient stages of sprawling upon agriculture lands in the north of Greater Cairo Region (GCR) abutting the ring road. (source: Google Earth)

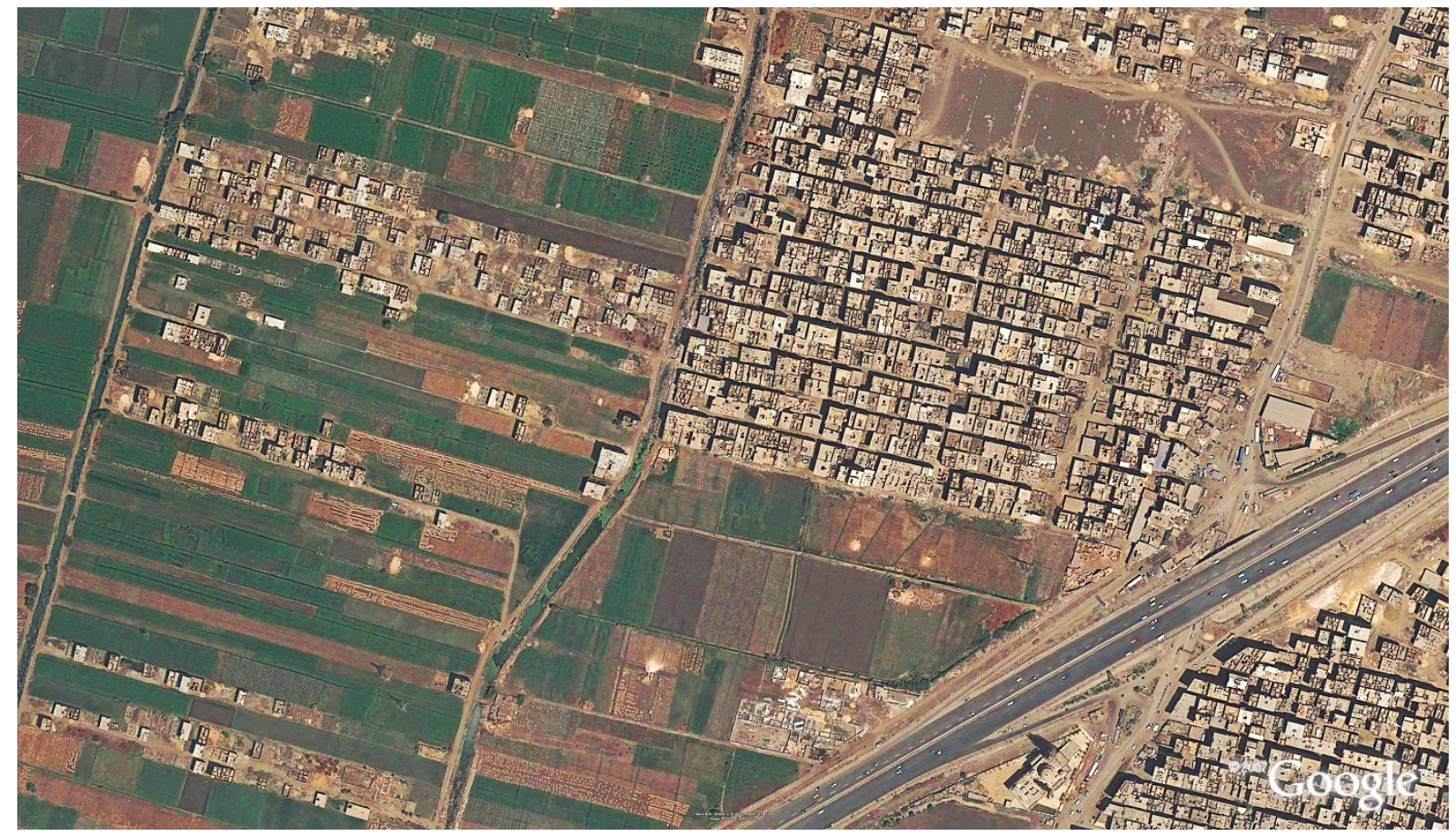

Fig. 4 - Older urban sprawling upon agriculture lands in the north of Greater Cairo Region (GCR) abutting the ring road. (source: Google Earth) 
enough to know that only 2 new cities in the GCR, i.e. 6th of October and New Cairo, have a combined area of $794.64 \mathrm{~km}^{2}$ which is almost double the area that holds the main agglomeration of GCR (12.23 million inhabitant in 2006) (Japan International Cooperation Agency and Ministry of Housing, Utilities and Urban Development 2008).

Boundaries extensions and wholesale infrastructure construction add to the sprawling problem that is already indubitable in the new desert cities. Foremost, they have low population densities not only during their filling period, including the GCR new cities (Japan International Cooperation Agency and Ministry of Housing, Utilities and Urban Development 2008), but also their targeted population densities are comparatively very low; ranging from 20 to 45 person per acre (NUCA 2014). This in turn precludes any hope for developing a cost effective public transportation in the future, already stumbling in highly densified areas.

In addition, habitation and construction dynamics within the new cities is fragmented: the mixture of vacant tracts of lands, skeletal structures, and splintered developments; being single buildings or gated communities; is a ubiquitous scene is almost all the cities. Finally, strict segregation of land uses is one of the planning norms in almost all their master plans; e.g. New Aswan, Badr and Al-Shorouk which typically will generate long travelling distances in an arid environment and climate unwelcoming to the active modes of transportations modes. Figures 5 and 6 illustrated examples of gated communities on the periphery of desert cities.

\section{Why the Middle Eastern Cities Sprawl?}

The phenomena behind sprawl in the Middle East is different from that of the West, from some points of view. The transformations of the urban settlements during the twentieth century and lack of control on these transformations look to be the general cause behind sprawl. The following presents a holistic look at the causes of sprawl in Egypt and Iran. Acknowledging the complexity of the phenomenon, multiple drivers contribute to sprawl in Egypt that can be classified also as social, economic, political drivers. These drivers within these three classifications inextricably intertwine to create the current optimum context for sprawling. Running through the genesis and evolution of each type allows us to uncover these drivers and their impact alongside with sprawling dynamics. What is interesting about sprawling in Egypt is that, political drivers have significant weight in both formal and informal sprawl in Egypt e.g. laws or decrees that were enacted regarding some former conditions (currently elapsed) but left decades in action, or extreme planning orientations to obviate futuristic possible malaises based on the current urban realism.

Lacking the necessary regulations, agriculture infringements germinated in early 1960s. They spiralled due to obliviousness of the sequential dispensations mainly absorbed in industrialization themes (Sims 2012) and edifice projects (Dorman 2013). In order to abate the phenomenon the government proscribed construction upon arable lands in 1983 (Law number 116) and toughened the punishment in 1996 decree $^{2}$. Still, infringements were victorious because their impetuses were and still are too powerful to be curbed through proscription only.

Two of the drivers of the informality phenomenon in Egypt in general and sprawling upon arable lands in specific are urbanization of the rural areas on the peripheries of the cities (Dorman 2013; Hareedy \& Deguchi 2011; Parker \& Coyle 1981), and the rural urban migration (Shaalan 2013; Shalaby 2012), although the pace of the second have declined substantially in the last 28 years especially to GCR (Sims 2012). One should ask, what stimulates people to build upon the current modicum of agriculture lands, not anywhere else, in apathy to the current proscription? Foremost, there is a fragmentation in the agriculture landholdings; which goes back to the 'Egyptian Land Reform' law in 1952 and its amendments in 1958, 1961 and 1969 limiting land ownerships by individuals to 200 feddan, 100 feddan and finally 50 feddan and allowing the proprietary of maximum of 5 feddan on long term instalments from the government. 


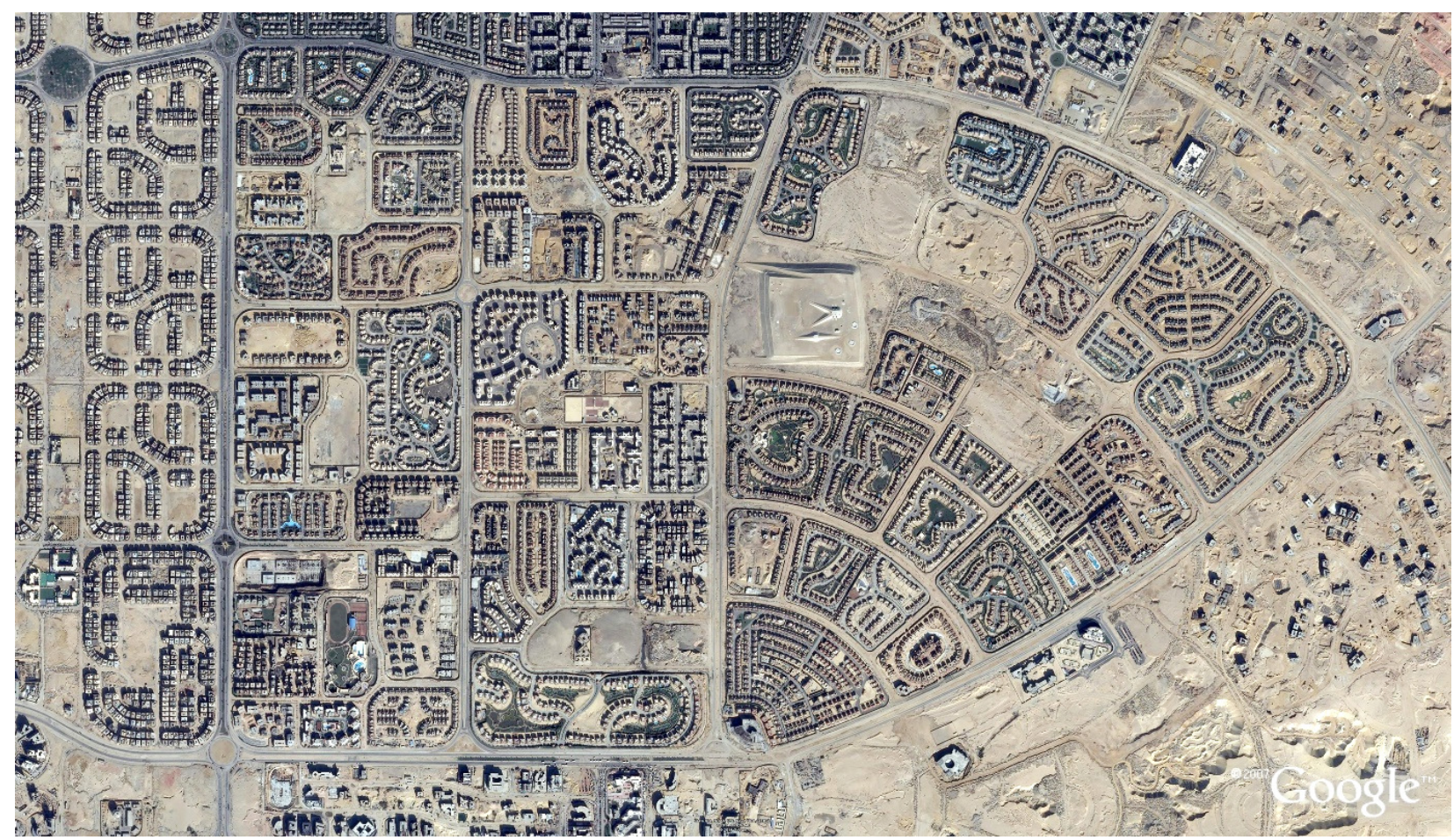

Fig. 5 - Gated communities in the desert city of New Cairo. (Source: Google Earth)

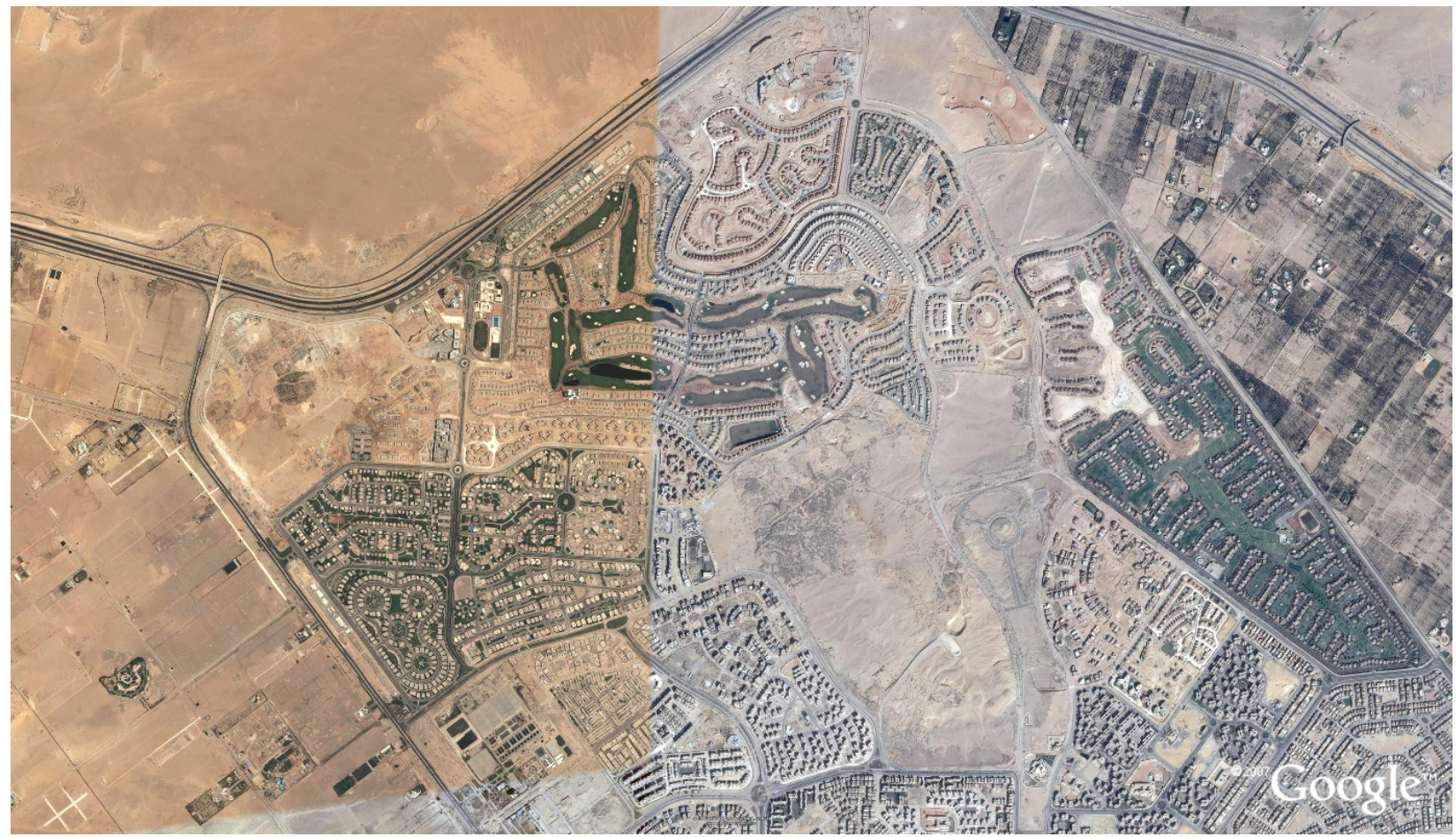

Fig. 6 - Gated communities and fragmented developments in the desert city of Sheihk Zayed.

(Source: Google Earth) 
After land conveyance through inheritance; landholdings became much smaller, in 2007, 80 percent of the landholdings were below 5 feddan and will continue to shrink further to below 3 feddan by 2025 (Kruseman \& Vullings 2007), also an ownership of only one Qirat of agriculture land $\left(175 \mathrm{~m}^{2}\right)$ is quite normal in Egypt (Sims 2012). This diminutive ownership curtails owners from generating any decent income (Shaalan 2013). Moreover, the market value of the land multiplies (up to eightfold) when transformed from agriculture use into building use which entices many farmers to do so. Infringements are usually commenced by individuals taking a risky (illegal) decision to construct residential buildings for personal or family use upon their subdivisions and many others typically follow, still surprisingly, in some cases infringements were germinated by public service buildings constructed by the government upon arable lands, as they can be legislatively exempted from the proscription.

Law enforcement mechanisms upon illegal infringements on the other hand are lax. Although, local authorities usually issue myriad of demolition decrees, there are multiple legislative loopholes to bypass them (Sims 2012). Enforcements, when they take place, are also arbitrary targeting only the brazen violations, and they are in any case a minuscule compared to the galloping phenomenon. Moreover, the desired ripple effect from the vociferous razzings, usually published in media (Werdany 2014), are brought to naught by the multiple other cases where infringements were completely or partially formalized through the sequential expansions and demarcations of the urban boundaries to include them (MHUUC 2014) or the provision of amenities under pressures from local communities which usually coincides with approaching parliamentary elections.

The desert new cities represent the formal facet of sprawling. Desert new cities are usually planned with very low population densities (vis-àvis the current urban population densities) and segregated land uses which is uncommon to the Egyptian context. These planning orientations along with the enforcement of very strict buildings regulations aim to forestall any possible scenario of degradation of the new desert cities towards informality or even over crowdedness (Hamza 2014), already evident in former projects. However, these conditions hike the costs of accommodation and commuting making new cities discordant to both the lower and the middle-income strata, while both income groups are already reluctant to move either away from their workplaces or from their families. After a prolonged failure to launch, developers and owners, with the support of the government, made an intrinsic shift in some cities towards upmarket apartments and compounds in order to attract the highest income quintile capable of moving, commuting and sustaining within such conditions. This quintile is mainly enticed or driven to invest or move to the new cities through a mixture speculative interests (Dorman 2013) and an urge to escape the degrading conditions in the old cities. As for the 'ghost cities' some are currently being re-planned to follow the path of the GCR new cities.

Interestingly, the planning and constructing new 'new cities' appear to be an autonomous process that pertinaciously progress disregarding any adverse conditions like the exorbitant costs, belated growth of the established ones and even their foreseen repercussions (e.g. planning to construct new administrative capital for Egypt on Suez road announced in 2014 under a struggling economy (Aman 2014)). The concept of New Cities appears to be safeguarded by a number of factors. Foremost, edifice construction projects represent a lopsided development track, which many countries exploit to eclipse other failures within their policies (Deboulet, 2010). Also, the policy of land sales (land disposal) adopted by the Government in 1990s began to bring incremental revenues particularly in the last 14 years, despite that fact that lands are being sold at prices lower than their market value (Sims 2012, p. 79). Unfortunately, this might mean that the policy of land sales and new cities might continue for quite some time instead on densifying and improving the management for the current ones.

In search for the main causes of sprawl in Iran, different types of societal, spatial, and economic issues have been studied in different languages. Obviously, most of the phenomena like attempts 
for modernization of the country, jump in the country's revenues in 1970s, importing automation technologies in the middle of the $20^{\text {th }}$ century, and the related societal changes caused by modernization work together, and it is not possible to detach them from one another. The economic drivers include issues like low price of farmlands and lands on the peripheral areas of the metropolitan cities, low commuting cost (with the government subsidizing the construction of new roads in the urban fringe and rural areas) and also low price of fuel, the influence of land speculators on the land market. Political /administrative drivers include poor master plans (which encourage the urban sprawl by annexation of land from rural areas and farmlands to the city like selling unlimited land on the periphery of cities after the 1979 revolution to people to build their own houses, instead of employing infill strategies or vertical growth), weak control on urban development plans, weak control on illegal constructions on the pre-urban areas such as what the so-called 'urban village', problematic land development legislation. Finally, the most important driver related to natural and Environmental issues is the geographical position of the city (whether it is close to any metropolitan areas, or any economic core of the country or the natural barriers, which can limit the urban growth of some cities).

\section{Conclusions}

In response to the two questions asked in this paper, the status of urban and suburban sprawl in the Middle Eastern cities was briefly described. According to the findings, in case the findings of Egypt and Iran are generalizable to a large part of the region (excluding some wealthier states of the region), the cities of different size in the region are sprawling. Of course, generalizability of the findings can be the topic of future studies and cannot be presented in this research article. Urban sprawl is not limited to large cities, but medium-sized and smaller cities are also sprawling. In Iran, not only large metropolitan areas like Tehran, Mashhad, Isfahan, Tabriz, and Shiraz but also Kashan (2011 population: 275325 inh.) and Babolsar (2006 population: 47872 inh.) sprawl.
In Egypt, new desert cities that often have limited population are urban sprawl pioneers.

The general characteristics of Egyptian sprawl can be brought under two main categories of sprawl upon desert and arable lands. Sprawl upon arable lands is very common in many cities of Iran, where dispersion takes place alongside outward routes over the gardens and agricultural land uses.

With rapid accumulation of evidences on presence of a development pattern that can be defined as urban sprawl in the Middle East, some of which were referred in this paper, a subject that was already raised and discussed to an extent of doubt (Masoumi 2014) is by more certainty proved: urban sprawl is an existent and growing phenomena in the Middle Eastern cities. This paper collects some more evidences about the severity of sprawl in the region.

Multifarious drivers have caused urban dispersal in the region, among which political and administrative causes seem to have heavier weight. The effects of political decisions on urban planning have had strong effects on urban population and its distribution. Mismanagement can be addressed in a long list of urban planning decisions and policies backed by lack of up-to-date knowledge of planning. Examples planning mismanagement is seen in the way density is allocated to new developments in the two countries. While the new developments in Egypt are planned based on low densities, it is attempted to block the growth of Iranian large metropolitan areas like Tehran under the name of 'urban sprawl containment', leading to lack of quality of life because of over densification and concentration of urban facilities on the city level.

\section{Notes \\ ${ }^{1}$ feddan $=4200$ square meter or 1,0378 acres. \\ ${ }^{2}$ The decree was revoked in 2005}

\section{Acknowledgement}

This paper is a summary of a part of a working paper published on the website of Center for Technology and society in Technische Universität Berlin. No funding was received to conduct this research. 


\section{References}

Ahmadi G, Azizi MM, Zebardast E (2011) Comparative study of city sprawl in three middle range cities of Iran: Ardabil, Sanandaj and Kashan. Journal of Architecture and Urban Planning (Iranian Journal) 3: 25-43.

Alonso W (1964) Location and land use. Toward a general theory of land rent. Harvard Unviersity Press.

Azimi N (2001) Structural changes in the city of Tabriz. Geographical Space Magazine (Iranian magazine).

Azizpour M, Hosseinzadeh Dalir K, Esmaeilpour N (2009) Investigation of Relationship between rapid horizontal growth of Yazd and population movements. Geography and Environmental Planning (Iranian journal published by University of Isfahan) 20: 105124.

Bin Ibrahim AL, Sabet Sarvestani MS (2009) Urban sprawl pattern recognition using remote sensing and GIS: case study Shiraz city, Iran, in: Urban Remote Sensing Event. Presented at the Urban Remote Sensing Event: 1-5.

Brueckner JK (2000) Property taxation and urban sprawl. Institute of Government and Public Affairs, University of Illinois.

Brueckner JK, Fansler DA (1983) The economics of urban sprawl: theory and evidence on the spatial sizes of cities. The Review of Economics and Statistics 65: 479-482.

Brueckner JK, Kim H-A (2003) Urban sprawl and the property tax. International Tax and Public Finance 10: 5-23.

Duany A, Plater-Zyberk E, Speck J (2001) Suburban nation: the rise of sprawl and the decline of the American dream. Farrar, Straus and Giroux.

Ebrahim zadeh Asmin H, Ebrahimzadeh E, Habibi M (2010) Analysis cause of physical expansion and growth sprawl Tabas city after of earthquake by using Holdren model. Geography and Development Magazine 19: 25-46.

Ewing R (1997) Is Los Angeles-style sprawl desirable? Journal of the American Planning Association 63: 107126.

Ewing R, Pendall R, Chen D (2002) Measuring sprawl and its impact, Smart Growth America. Washington, DC.

Franz G, Maier G, Schröck P (2006) Urban sprawl: how useful is this concept? European Regional Science Association, Vienna.

Ghanavati E, Azimi A, Faraji Mollaie A (2012) The environmental quality of city and urban sprawl in
Babolsar. Human Geography Research Quarterly 44: 28-30.

Hendrickx M, De Laet V, Stal C, De Wulf A, Goossens R (2013) The use of high resolution digital surface models for change detection and viewed analysis in the urban area around the pyramids of Giza, Egypt, in: Urban Remote Sensing Event (JURSE). Presented at the Urban Remote Sensing Event (JURSE): 21-24.

Hosseini SA (2008) The analyzing of Mashhad city sprawl and its effect on the soil and water resources (MA thesis in Geography and Urban Planning). University of Tehran.

Hosseini S A, Shahraki SZ, Farhudi R, Hosseini SM, Salari M, Pourahmad A (2010) Effect of urban sprawl on a traditional water system (qanat) in the City of Mashhad. Urban Water Journal 7: 309-320.

Jaeger JAG, Bertiller R, Schwick C, Kienast F (2010) Suitability criteria for measures of urban sprawl. Ecological Indicators 10: 397-406.

Japan International Cooperation Agency, Ministry of Housing, Utilities and Urban Development (2008) The strategic urban development master plan study for sustainable development for sustainable development in the Arab Republic Of Egypt. JICA, Cairo.

Kipper R, Fischer M (2009 eds.) Cairo's informal areas between urban challenges and hidden potentials: facts. voices. Visions, GTZ Egypt, Participatory Development Programme in Urban Areas (PDP).

Mahmoudabadi SE, Soroushnia R, Zekri A (2013) Evaluating Iranian urban development plants in order to develop a development plan for Sirjan City of Iran. Technical Journal of Engineering and Applied Sciences 3(19): 2365-2370.

Margo RA (1992) Explaining the postwar suburbanization of population in the United States: the role of income. Journal of Urban Economics 31: 301-310.

Masoumi HE (2012a) Urban sprawl in Iranian cities and its differences with the western sprawl. Spatium International Review 27: 12-18.

Masoumi HE (2012b) A new approach to the Iranian urban planning, using neo-traditional development, PhD dissertation, Faculty of Spatial Planning, Technical University of Dortmund, Germany.

Masoumi HE (2014) Urban sprawl in mid-sized cities of MENA, evidence from Yazd and Kashan in central Iran. Management Research and Practice 6(2): 25-41.

Masoumi HE, Roque D (2015) Evaluation of urban sprawl speed and intensity based on international urbanization, example from a Mexican city. Journal of Settlements and Spatial Planning 6(1): 27-35. 
McGrath DT (2005) More evidence on the spatial scale of cities. Journal of Urban Economics 58: 1-10. doi:10.1016/j.jue.2005.01.003

Mills ES (1972) Studies in the structure of the urban economy. Johns Hopkins Press.

Mirkatoli J, Ghadami M, Mahdian BM, Mohammadi S (2011) Study and survey of trend and physical-space expansion of Babolsar city with using Shannon's Entropy and Holdern models. Journal of Geographical Landscape 6: 26-29.

Mobaraki O, Mohammadi J, Zarabi A (2012) Urban form and sustainable development: The case of Urmia City. Journal of Geography and Geology 4(2): 1-12.

Mobaraki O, Mohammadi J, Zarrabi A (2013) Presentating the optimum pattern for physical- spatial development of Urmia City. Geography and Development (Iranian Journal) 11(32): 75-88.

Mokhtari R, Hoseinzadeh R, Safaralizadeh E (2015) An analyze of smart growth patterns in fourteen areas of Isfahan metropolitan, based on regional planning models. Journal of Urban - Regional Studies and Research 5(19): 11-14.

Movahed K (2004) A study on the dwindling of Shiraz green areas. Proceedings of 40th ISoCaRP Congress: 18-22.

Muth R (1969) Cities and housing: The spatial patterns of urban residential land use. University of Chicago, Chicago.

Nechyba T J, Walsh R P (2004) Urban Sprawl. The Journal of Economic Perspectives 18: 177-200.

Patacchini E, Zenou Y, Henderson J V, Epple D (2009) Urban sprawl in Europe. Brookings-Wharton Papers on Urban Affairs 125-149.

Pourahmad A, Baghvand A, Zangenehe Shahraki S, Givehchi S (2007) The impact of urban sprawl up on air pollution. International Journal of Environmental Research 1(3): 252-257.

Pourmohammadi M, Jame Kasra M (2011) An analysis of the Tabriz sprawl pattern 26: 31-54.

Ragheb K (2014) Sis's Plan for the New Roads. Almasry Alyoum 19.08.2014 (Egyptian Newspaper).

Rafiee R, Mahiny AS, Khorasani N, Darvishsefat AA, Danekar A (2009) Simulating urban growth in Mashad
City, Iran through the SLEUTH model (UGM). Cities 26: 19-26.

Roshan GR, Shahraki S Z, Sauri D (2010) Urban sprawl and climatic changes in Tehran. Iranian Journal of Environmental Health Science \& Engineering 7, 43-52.

Roshan G, Rousta I, Ramesh M (2009) Studying the effects of urban sprawl of metropolis on tourismclimate index oscillation: a case study of Tehran city. Journal of Geography and Regional Planning 2: 310321.

Sabet Sarvestani M, Ibrahim A L, Kanaroglou P (2011) Three decades of urban growth in the city of Shiraz, Iran: A remote sensing and geographic information systems application. Cities 28, 320-329.

Sandal EK, Gurbuz M (2003) The examination of spatial expansion of the city of Mersin and misuse of agricultural lands: Turkish Journal of Geographical Sciences. 1, 117-130.

Sierra Club (1998) Sprawl: the dark side of the American dream. Sierra Club, San Francisco, CA.

Sims D (2012) Understanding Cairo: the logic of a city out of control. The American University in Cairo Press.

Soffianian A, Nadoushan MA, Yaghmaei L, Falahatkar S (2010) Mapping and analyzing urban expansion using remotely sensed imagery in Isfahan, Iran. World Applied Sciences Journal 9, 1370-1378.

The Cabinet IDSC (2007) Cars in Egypt, Facts and Figures. The Cabinet, Information and Decision Support Center (IDSC), Cairo.

The World Bank (2015) World Development Indicators (WDI). February 2015.

Torrens PM (2008) A toolkit for measuring sprawl. Applied Spatial Analysis and Policy 1: 5-36.

U S Department of Housing and Urban Development (1999) The state of the cities 1999: third annual report. Washington, DC.

Wassmer RW (2002) An economic perspective on urban sprawl. California: California Senate Office of Research.

Zanganeh Shahraki S, Sauri D, Serra P, Modugno S, Seifolddini F, Pourahmad A (2011) Urban sprawl pattern and land-use change detection in Yazd, Iran. Habitat International 35, 521-528. 